\title{
Transatlantica
}

Revue d'études américaines. American Studies Journal

\section{Kevin J. Kayes. Poe and the Printed Word.}

Cambridge : Cambridge University Press, 2000. 148p. ISBN 0-521-66276-1.

\section{Anne Garrait-Bourrier}

\section{CpenEdition}

Journals

Édition électronique

URL : http://journals.openedition.org/transatlantica/699

DOI : $10.4000 /$ transatlantica.699

ISSN : $1765-2766$

Éditeur

AFEA

Référence électronique

Anne Garrait-Bourrier, « Kevin J. Kayes. Poe and the Printed Word. », Transatlantica [En ligne], 1 | 2003,

mis en ligne le 05 avril 2006, consulté le 29 avril 2021. URL : http://journals.openedition.org/

transatlantica/699; DOI : https://doi.org/10.4000/transatlantica.699

Ce document a été généré automatiquement le 29 avril 2021.

\section{(c) (i)}

Transatlantica - Revue d'études américaines est mis à disposition selon les termes de la licence Creative Commons Attribution - Pas d'Utilisation Commerciale - Pas de Modification 4.0 International. 


\title{
Kevin J. Kayes. Poe and the Printed Word.
}

Cambridge : Cambridge University Press, 2000. 148p. ISBN 0-521-66276-1.

\author{
Anne Garrait-Bourrier
}

1 Kevin Hayes est Associate Professor à l'université d'Oklahoma. Spécialiste de culture américaine, il a publié de nombreux ouvrages sur le livre et sur le monde de l'édition aux Etats-Unis, en particulier A Colonial Woman's Bookshelf (1996) ou Folklore and Book Culture (1997). Il s'est également intéressé à certains écrivains canoniques américains comme Melville, auquel il a consacré trois ouvrages, et Henry James.

L'ouvrage qui nous intéresse ici réunit en fait les deux centres d'intérêt de Hayes: l'étude du monde du livre et de l'édition américaine et le parcours d'un écrivain au cœur de cet univers. Pour ce faire, l'auteur choisit un écrivain dont les choix éditoriaux ont souvent été dictés par les modes littéraires de son temps: Edgar Allan Poe.

L'ouvrage, conçu de façon très pédagogique, est de lecture aisée. Le lecteur emboîte le pas de Hayes dans son double projet chronologique et thématique : suivre Edgar Allan Poe, ses prises de décisions, ses orientations artistiques au fil du temps, tout en observant simultanément le milieu de l'édition américaine, ses contraintes et ses limites. Hayes partage ainsi son ouvrage en huit chapitres brefs - d'une vingtaine de pages chacun - organisés autour d'un thème plus ou moins directement rattaché au monde du livre. Pour ne citer que quelques exemples, notons que le chapitre introductif s'intitule assez vaguement "The Student and the Book » puisqu'il ne vise qu'à poser la problématique c'est-à-dire, définir les liens existant entre Poe et le livre, une problématique qui sera développée de façon plus systématiquement culturaliste dans le cours de l'ouvrage. Ainsi, dès le chapitre deux, "Poetry in Manuscript and Print ", Hayes arrive au cœur de son analyse en démontrant par quels biais Poe s'inscrit dans la culture éditoriale de son pays pour publier ses premiers poèmes. Hayes s'appuie sur les analyses d'un autre culturaliste américain spécialiste de l'écrit, Donald $\mathrm{H}$. Reiman (The Study of Modern Manuscripts : Confidential, and Private. Baltimore: John 
Hopkins UP, 1993), afin de souligner le pas franchi par Poe en passant d'une écriture de soi à une écriture publique répondant à des normes imposées.

Cet ouvrage, à la bibliographie clairement orientée vers le monde de l'édition, offre un regard très documenté sur la seconde proposition du titre, c'est-à-dire, «the Printed Word». Il apparaît donc qu'il ne s'agit pas ici d'un travail d'analyse littéraire sur l'œuvre de Poe, malgré la présence au chapitre cinq de pages très éclairantes sur les origines du texte poesque Gordon Pym. Le parcours de Poe ne semble en fait être utilisé par Hayes que comme une sorte de toile de fond idéale pour souligner l'évolution des goûts du public américain dans le cours du XIX siècle depuis les feuilletons publiés dans les gazettes, aux nouvelles indépendantes; puis des recueils de nouvelles aux romans, et enfin des romans, devenus trop indigestes, aux feuilletons de qualité. Et il faut bien reconnaître que cet ouvrage nous convainc aisément qu'il ne pouvait sans doute pas y avoir de meilleur exemple que celui de Poe pour illustrer ce que fut la dictature du public en matière éditoriale et les contraintes des modes littéraires au XIX siècle. Poe présentait en effet tous les aspects de l'auteur «dépendant» des modes éditoriales.

L'ouvrage de Hayes est un essai qui traite d'un point précis de la culture américaine. Il renseignera également tous ceux qui cherchent à découvrir Edgar Allan Poe et veulent en savoir davantage sur sa personnalité et sa vision du métier d'écrivain. Il se pourrait cependant qu'il laisse les lecteurs spécialistes du texte même d'Edgar Allan Poe légèrement sur leur faim car aucune étude de fond n'est menée dans ce domaine malgré un titre qui peut sans doute laisser espérer une approche structuraliste de l'œuvre de Poe («Poe and the Printed Word » peut en effet laisser sous-entendre une étude détaillée des œuvres publiées de Poe...). Hormis cette légère confusion possible dans le titre même de l'ouvrage, Hayes prévient d'emblée ses lecteurs de son double projet à la fois culturaliste et biographique, ce qui suffit dès les premières pages à lever toute ambiguïté.

INDEX

Thèmes : Recensions

\section{AUTEUR}

ANNE GARRAIT-BOURRIER

Clermont II 